\title{
Two distinct signaling pathways regulate peroxynitrite-induced apoptosis in PC12 cells
}

\author{
JJ Shacka ${ }^{1,6}$, MA Garner ${ }^{2}$, JD Gonzalez ${ }^{1}, Y_{-Z}$ Ye $^{1,7}$, \\ TL D'Alessandro ${ }^{3}$ and AG Estévez ${ }^{\star, 1,4,5,7}$ \\ ${ }^{1}$ Department of Physiology and Biophysics, University of Alabama at \\ Birmingham, Birmingham, AL, USA \\ ${ }^{2}$ Burke/Cornell Medical Research Institute, White Plains, NY, USA \\ 3 Department of Pharmacology and Toxicology, University of Alabama at \\ Birmingham, Birmingham, AL, USA \\ 4 Department of Neurobiology, University of Alabama at Birmingham, \\ Birmingham, AL, USA \\ ${ }^{5}$ Center for Free Radical Biology, University of Alabama at Birmingham, \\ Birmingham, AL, USA \\ 6 Current address: Division of Neuropathology, Department of Pathology, \\ University of Alabama at Birmingham, Birmingham, AL 35294, USA \\ 7 Current address: Burke/Cornell Medical Research Institute, White Plains, NY \\ 10605, USA \\ * Corresponding author: AG Estévez, Laboratory of Motor Neuron Biology, \\ Burke/Cornell Medical Research Institute, 785 Mamaroneck Ave, White Plains, \\ NY 10605, USA. Tel: + 1914597 5221; Fax: + 1914597 5222; \\ E-mail: aestevez@burke.org
}

Received 28.2.05; revised 25.10.05; accepted 02.11.05; published online 20.1.06 Edited by M Miura

\begin{abstract}
The mechanisms of peroxynitrite-induced apoptosis are not fully understood. We report here that peroxynitrite-induced apoptosis of PC12 cells requires the simultaneous activation of $\mathrm{p} 38$ and JNK MAP kinase, which in turn activates the intrinsic apoptotic pathway, as evidenced by Bax translocation to the mitochondria, cytochrome $c$ release to the cytoplasm and activation of caspases, leading to cell death. Peroxynitrite induces inactivation of the Akt pathway. Furthermore, overexpression of constitutively active Akt inhibits both peroxynitrite-induced Bax translocation and cell death. Peroxynitrite-induced death was prevented by overexpression of Bcl-2 and by cyclosporin A, implicating the involvement of the intrinsic apoptotic pathway. Selective inhibition of mixed lineage kinase (MLK), p38 or JNK does not attenuate the decrease in Akt phosphorylation showing that inactivation of the Akt pathway occurs independently of the MLK/MAPK pathway. Together, these results reveal that peroxynitrite-induced activation of the intrinsic apoptotic pathway involves interactions with the MLK/MAPK and Akt signaling pathways.

Cell Death and Differentiation (2006) 13, 1506-1514.

doi:10.1038/sj.cdd.4401831; published online 20 January 2006
\end{abstract}

Keywords: peroxynitrite; apoptosis; mitochondria; MAPK; Akt

Abbreviations: PI3-K, phosphatidyl inositol 3-kinase; MAPK, mitogen-activated protein kinase; MLK, mixed lineage kinase; JNK, c-Jun- $N$-terminal kinase

\section{Introduction}

Nitric oxide regulates synaptic transmission, synaptogenesis and cell survival, while contributing to the pathogenesis of neurological diseases and cerebral ischemia. ${ }^{1}$ Nitric oxide is a relatively unreactive molecule, with reactivity comparable to that of molecular oxygen. ${ }^{1}$ However, nitric oxide reacts with superoxide to form the powerful oxidant peroxynitrite. Peroxynitrite is formed at a rate more than three times faster than the scavenging of superoxide by superoxide dismutase. ${ }^{1}$ Under pathological conditions, the production of nitric oxide is overstimulated, leading to the formation of peroxynitrite, which mediates the deleterious effects of nitric oxide and superoxide. $^{1}$

Peroxynitrite has a relatively short half-life $(<1 \mathrm{~s}$ in physiological conditions). It has distinct biological targets, including lipids, thiols and tyrosine residues. ${ }^{1,2}$ Increased nitrotyrosine immunoreactivity is a common feature in several pathological conditions, including atherosclerosis, rheumatoid arthritis and neurodegenerative diseases. ${ }^{1,3}$ Even though the formation of nitrotyrosine is not a 'footprint' for peroxynitrite formation, ${ }^{4}$ it is reasonable to suggest that if nitric oxide and superoxide are formed, peroxynitrite is also produced.

Peroxynitrite induces apoptosis in a number of cell types in culture, including pheochromocytoma-derived PC12 cells, 5,6 cortical neurons, ${ }^{7}$ HL- 60 cells $^{8}$ and rat thymocytes. ${ }^{9}$ Peroxynitrite-induced apoptosis of PC12 cells can be prevented by pretreatment with nerve growth factor (NGF), insulin and caspase inhibitors. ${ }^{5}$ Treatment with peroxynitrite also decreases the activity of the phosphatidyl-inositol 3-kinase (PI3-K) pathway, ${ }^{6}$ while stimulating the activity of $p 38^{10}$ and c-Jun- $N$-terminal kinase (JNK) mitogen-activated protein kinase (MAPK) pathways. ${ }^{11}$ Both the inactivation of $\mathrm{PI}-\mathrm{K}^{12}$ and the activation of $\mathrm{p} 38$ and JNK/MAPK ${ }^{13}$ have been shown to promote apoptosis. Furthermore, activation of $\mathrm{PI}-\mathrm{K}$ is important in preventing apoptotic signaling in PC12 cells. ${ }^{12}$ These observations suggest that peroxynitrite-induced cell death might result from the activation of specific apoptotic signaling pathways and not merely from nonspecific oxidative damage. However the intracellular signaling pathways responsible for peroxynitrite-induced apoptosis are still poorly understood. In this study, we sought to determine the roles played by the mixed lineage kinase (MLK)/MAPK and Akt signaling pathways in the peroxynitrite-induced apoptosis of PC12 cells.

\section{Results}

Incubation of PC12 cells with $0.5 \mathrm{mM}$ peroxynitrite induced the transient phosphorylation of p38 and JNK MAP kinases (Figure 1a and b), as measured in whole cell lysates. Phosphorylation of both kinases was maximal 15-20 min after exposure to peroxynitrite. Phospho-p38 returned to basal levels within $4 \mathrm{~h}$ (Figure 1a) and phospho-JNK within $2 \mathrm{~h}$ (Figure 1b) following treatment. The contribution of activated 


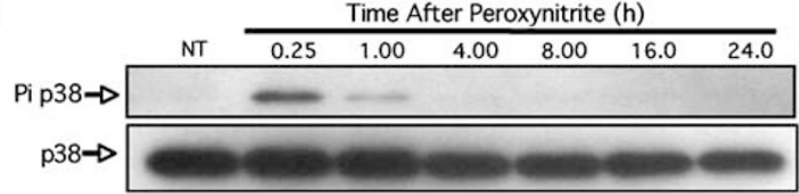

b

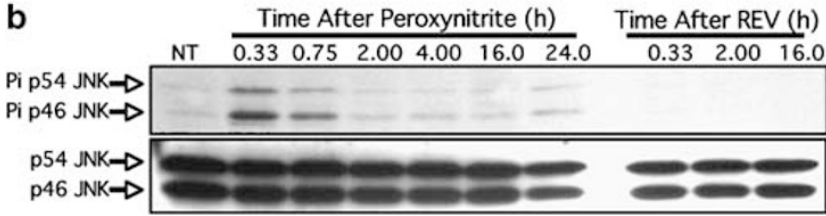

C

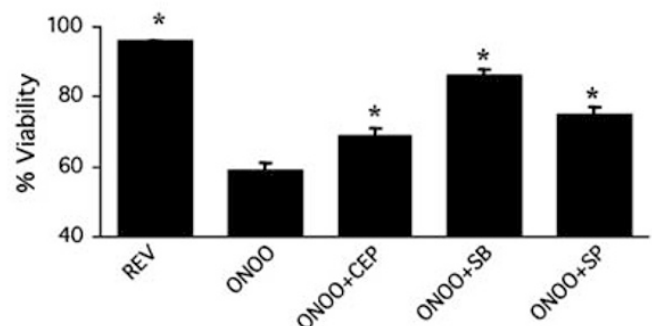

Figure 1 Peroxynitrite activated p38 and JNK MAP kinase. (a, b) Representative Western blots show phosphorylation of p38 and JNK MAP kinase following treatment with peroxynitrite $(0.5 \mathrm{mM})$. Blots probed for the phosphorylated forms of p38 and JNK were stripped and subsequently probed using antibodies against total p38 and JNK. Activation of p38 and JNK occurred within minutes and was maximal within $1 \mathrm{~h}$ (JNK) and $4 \mathrm{~h}$ (p38) following treatment. (c) Inhibition of MLK (CEP11004, $1 \mu \mathrm{M})$, p38 (SB203580, $1 \mu \mathrm{M})$ or JNK (SP600125 $0.1 \mu \mathrm{M})$ significantly prevented cell death induced by peroxynitrite (ONOO), but the combined inhibition of p38 and JNK, or the combined inhibition of p38, JNK and MLK did not offer any additional protection. REV = reverse order addition (decomposed peroxynitrite). NT $=$ no treatment control. Viability results represent means \pm S.E.M. of duplicate measures from at least three independent experiments. ${ }^{*} P<0.05$ versus peroxynitrite

p38 and JNK to peroxynitrite-induced cell death was determined by measuring cell viability in the presence of inhibitors selective for p38 (SB203580, $1 \mu \mathrm{M})$, JNK (SP600125, $0.1 \mu \mathrm{M})$ or MLK (CEP11004, $1 \mu \mathrm{M}$ ) (Figure 1c). The selective inhibition of $\mathrm{p38}$, JNK or MLK significantly decreased peroxynitrite-induced cell death. However, the combined inhibition of $\mathrm{p} 38$ and JNK, or the combined inhibition of p38, JNK and MLK did not provide any additional protection in comparison to treatment with each inhibitor alone.

JNK MAPK has been shown to translocate from the cytosol to the mitochondria in a stimulus-dependent fashion. ${ }^{14,15}$ To determine if peroxynitrite differentially affected the localization of activated JNK, PC12 cells were treated with $0.5 \mathrm{mM}$ peroxynitrite, incubated for $20 \mathrm{~min}$ and subcellular fractions were collected for analysis of phosphorylated p46JNK and phosphorylated p54JNK (Figure 2a and b). Peroxynitrite significantly increased total cellular levels of phosphorylated p54JNK in comparison to control (reverse order addition or decomposed peroxynitrite). Peroxynitrite also augmented the phosphorylation of p46JNK and p54JNK in mitochondrial fractions in comparison to control. Levels of cytosolic and mitochondrial p46JNK and p54JNK were measured as a fraction of total cellular JNK (Figure 2a and c). Compared to control, levels of p46JNK were significantly higher in the cytosolic fraction: levels of p54JNK were significantly higher in
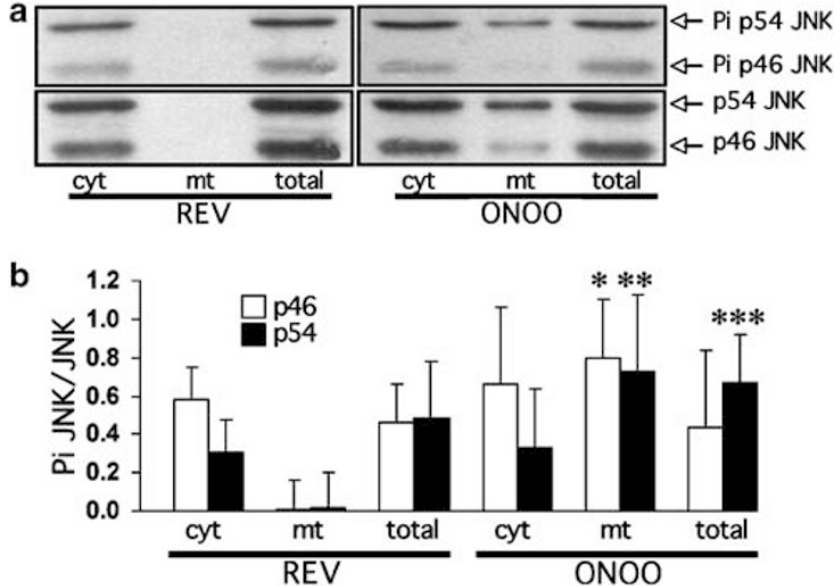

C

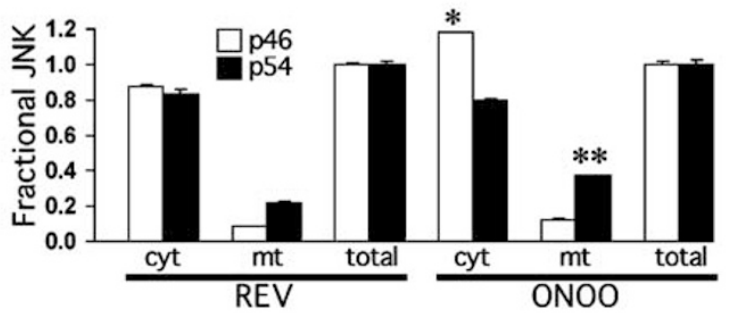

d

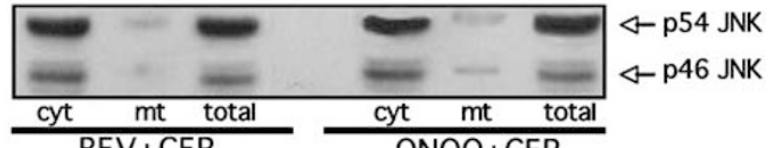

e

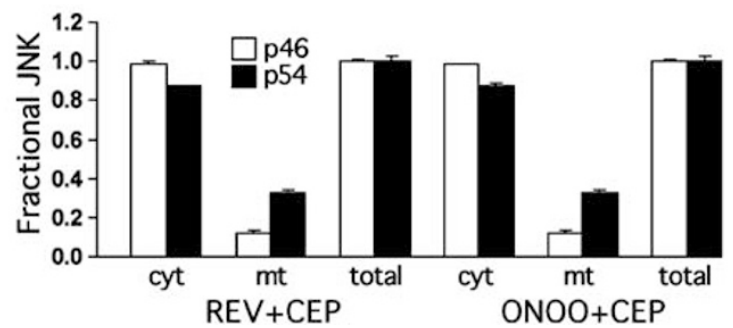

Figure 2 Peroxynitrite induced translocation of JNK and phospho-JNK to the mitochondrial fraction. Whole-cell lysates (total) were collected $25 \mathrm{~min}$ following treatment with $0.5 \mathrm{mM}$ peroxynitrite and processed into cytosolic (cyt) and mitochondrial (mt) fractions. Blots were probed with an antibody selective for the active or phosphorylated form of JNK, then stripped and subsequently probed with an antibody selective for total JNK. (a) Representative Western blots indicate subcellular alterations in phospho-p46/p54 JNK and p46/p54 JNK. (b) Values for phospho-p46 JNK (open bars) and phospho-p54 JNK (filled bars) were normalized to phosphorylated plus nonphosphorylated p46 JNK and p54 JNK, respectively. The values represent the mean + S.E.M. of the optical density ratio from three independent experiments. Peroxynitrite (ONOO) induced a significant increases in phospho-p46 JNK/p46 JNK $\left({ }^{*} P<0.05\right)$ and phospho-p54 JNK/p54 JNK $\left({ }^{* *} P<0.05\right)$ in mitochondrial fractions. Total phospho-p54 JNK/p54 JNK was significantly $\left.{ }^{* * \star} P<0.05\right)$ higher when treated with peroxynitrite. (c) Values for p46 JNK (open bars) and p54 JNK (filled bars) for each fraction were normalized to total levels of p46 JNK and p54 JNK and are represented graphically. The values represent the mean \pm S.E.M. of the standardized optical density of the bands from three independent experiments. Peroxynitrite induced significant increases in cytosolic p46 JNK ( ${ }^{\star} P<0.05$ ) and mitochondrial p54 JNK $\left({ }^{*} P<0.05\right)$. (d) Representative Western blot shows that the inhibition of MLK (CEP11004, 1 $\mu \mathrm{M}$ ) prevented peroxynitrite-induced increases in cytosolic p46 JNK and mitochondrial p54 JNK, represented graphically in panel (e). Open bars represent $\mathrm{p} 46 \mathrm{JNK}$; filled bars represent $\mathrm{p} 54 \mathrm{JNK}$. REV = reverse order addition (decomposed peroxynitrite). Results represent mean \pm S.E.M. of five independent experiments 
the mitochondrial fraction. The selective inhibition of MLK with CEP11004 $(1 \mu \mathrm{M})$ prevented the peroxynitrite-induced translocation of p46JNK and p54JNK (Figure 2d and e). Similar experiments designed to study the effects of peroxynitrite on p38 localization reveal that incubation of PC12 cells with peroxynitrite did not induce the translocation of either phospho p38 or p38 to the mitochondria (data not shown).

Treatment with $0.5 \mathrm{mM}$ peroxynitrite increased the ratio of mitochondrial to cytosolic Bax (Figure $3 a$ and b) and decreased the ratio of mitochondrial to cytosolic cytochrome
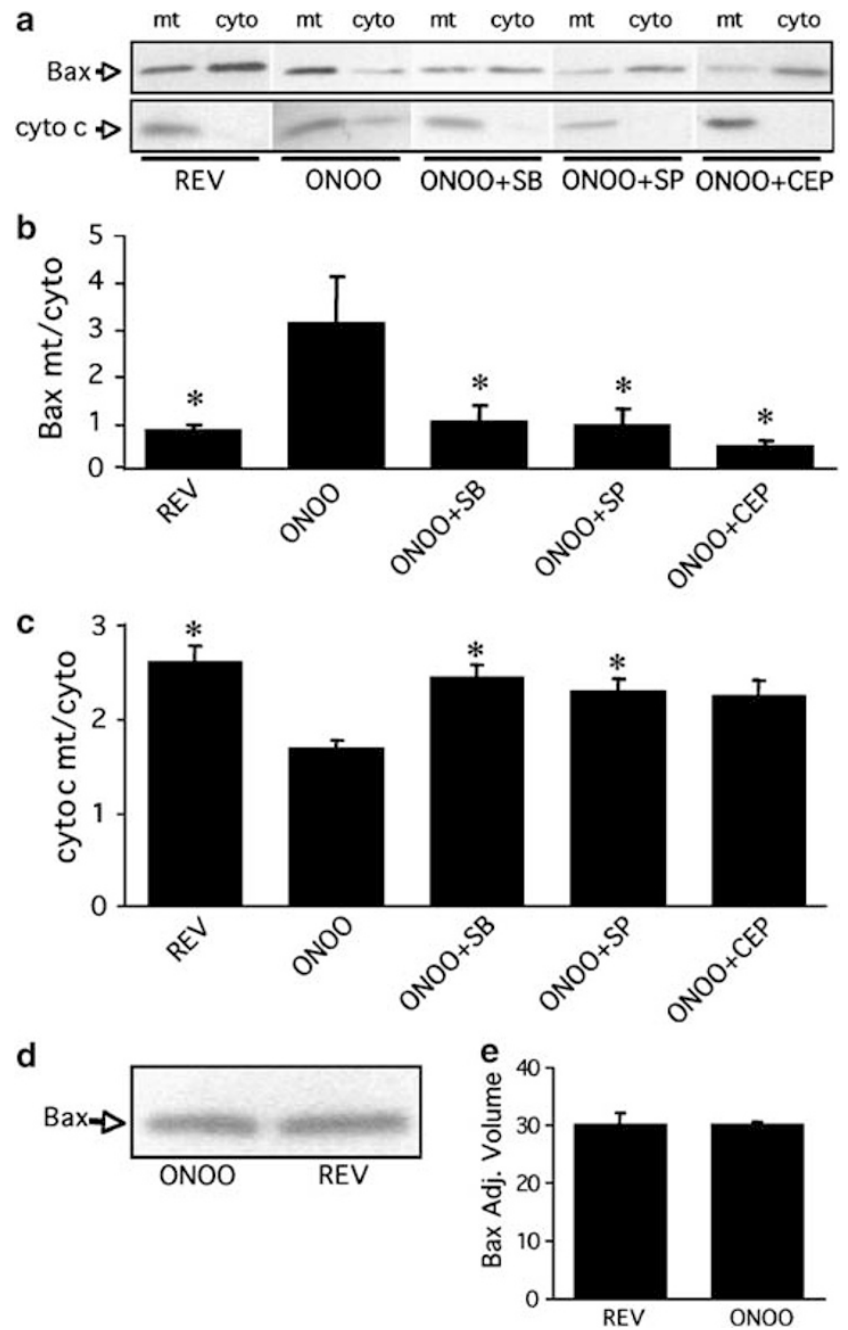

Figure 3 Peroxynitrite induced the translocation of Bax and release of cytochrome c. (a) Representative Western blot shows peroxynitrite (ONOO)induced translocation of Bax from the cytosolic to mitochondrial fraction, and release of cytochrome $c$ from the mitochondrial to cytosolic fraction. Inhibitors selective for p38 (SB203580, $1.0 \mu \mathrm{M})$, JNK (SP600125, $0.1 \mu \mathrm{M})$ and MLK (CEP11004, 1.0 $\mu \mathrm{M})$ attenuate this peroxynitrite-induced translocation of Bax and the release of cytochrome $c$. Western blot data are expressed quantitatively in panels (b) and (c) as the ratio of mitochondrial to cytosolic Bax and to cytochrome $c$, respectively. (d) Representative Western blot of whole-cell lysates indicates that peroxynitrite does not affect total cellular Bax, which is represented graphically in panel (e). Results represent means \pm S.E.M. of at least three independent experiments. All proteins were collected $16 \mathrm{~h}$ following treatment with $0.5 \mathrm{mM}$ peroxynitrite. $\mathrm{REV}=$ reverse order addition (decomposed peroxynitrite). ${ }^{*} P<0.05$ versus peroxynitrite c (Figure 3a and c), without affecting the total cellular content of Bax (Figure 3d and e). The selective inhibition of p38, JNK and MLK significantly attenuated the peroxynitrite-induced increase in mitochondrial to cytosolic Bax ratio (Figure $3 a$ and b). In addition, the selective inhibition of p38 and JNK significantly prevented the peroxynitrite-induced release of cytochrome $c$ from the mitochondria (Figure $3 a$ and $c$ ). Although the selective inhibition of MLK attenuated the peroxynitrite-induced decrease in the ratio of mitochondrial to cytosolic cytochrome $c$, the effect did not reach statistical significance (Figure 3c).

Peroxynitrite $(0.5 \mathrm{mM})$ induced the cleavage of both caspase 9 (Figure $4 a$ and b) and caspase 3 (Figure 4a and c) at 16 and $24 \mathrm{~h}$ following treatment. The peroxynitriteinduced cleavage of caspase 3 correlated with the cleavage of its substrate PARP (Figure 4d). Furthermore, the percentage of TUNEL-positive cells was significantly higher at $16 \mathrm{~h}$ following treatment with peroxynitrite (Figure $4 e$ and $f$ ), coinciding with the onset of caspase cleavage.

The peroxynitrite-induced activation of caspase 3 was concentration dependent and was maximal at $0.5 \mathrm{mM}$ (Figure $5 \mathrm{a}$ and $\mathrm{b}$ ), as measured $16 \mathrm{~h}$ following treatment. Peroxynitrite also induced a concentration-dependent decrease in cell viability (Figure 5c), with the largest decrease seen at $1.0 \mathrm{mM}$ peroxynitrite, the highest concentration tested. The peroxynitrite-induced activation of caspase 3 was significantly inhibited at $16 \mathrm{~h}$ following selective inhibition of MLK (Figure $5 \mathrm{~d}$ and $\mathrm{e})$. The cleavage of caspase 3 was similarly prevented by selective inhibition of either p38 or JNK (data not shown). Furthermore, treatment with the general caspase inhibitor z-VAD-fmk, as well as with inhibitors selective for caspases 3 and 9 (z-DEVD-fmk and z-LEHD-fmk, respectively), significantly inhibited peroxynitrite-induced cell death (Figure $5 f$ ).

The overexpression of $\mathrm{Bcl}-2$ inhibited the peroxynitriteinduced cleavage of caspases 9 and 3 (Figure 6a) and increased the resistance of PC12 cells to peroxynitriteinduced cell death (Figure 6b). In addition, incubation with cyclosporin $\mathrm{A}(2.5 \mu \mathrm{M})$, an inhibitor of the mitochondrial permeability transition, ${ }^{16}$ significantly attenuated peroxynitrite-induced cell death (Figure 6c). Lower concentrations of cyclosporin $\mathrm{A}(0.5$ and $1.0 \mu \mathrm{M})$ also prevented cell death (data not shown).

Next, we assessed the effects of peroxynitrite on the PI3-K/ Akt pathway. Peroxynitrite $(0.5 \mathrm{mM})$ decreased the phosphorylation of Akt in PC12 cells at $16 \mathrm{~h}$ following treatment (Figure $7 \mathrm{a}$ and $\mathrm{b})$, an effect that was not attenuated by selective inhibition of p38, JNK or MLK (Figure 7c and d). To determine the relevance of the Akt pathway in peroxynitrite-induced death, cell viability was measured following the transient cotransfection of PC12 cells with GFP and constitutively active Akt, in comparison to the transient transfection with GFP alone (Figure 8). The overexpression of constitutively active Akt significantly attenuated the peroxynitrite-induced death of GFP-positive PC12 cells in comparision to transfection with GFP alone (Figure 8a). In addition, the overexpression of constitutively active Akt significantly attenuated the peroxynitrite-induced increase in the ratio of mitochondrial to cytosolic Bax (Figure $8 b$ and $c$ ). The overexpression of Akt in PC12 cells was confirmed via Western blot (Figure 8d). 
a

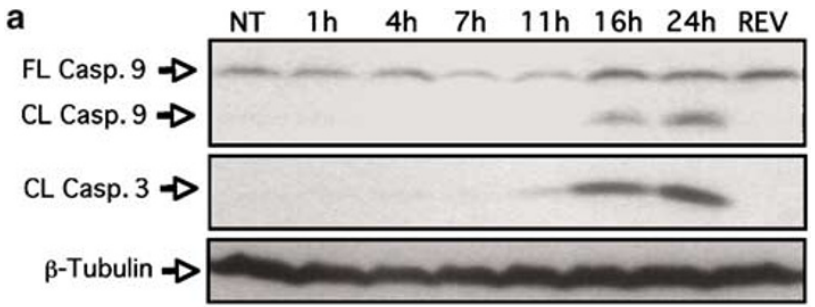

b
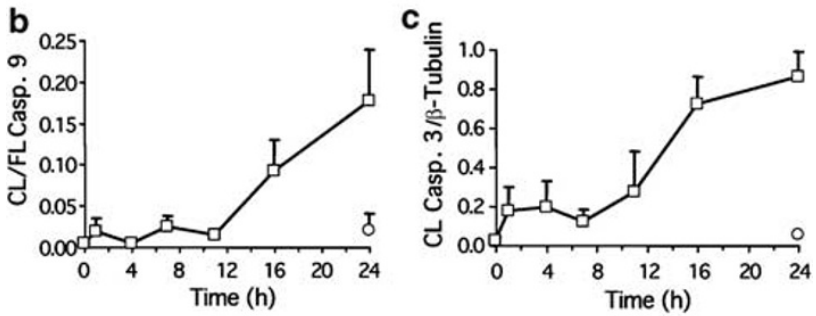

d

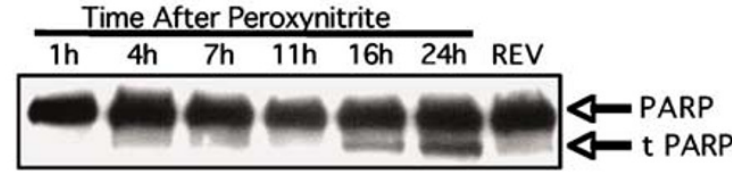

e

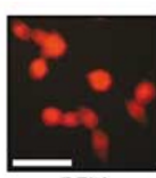

REV

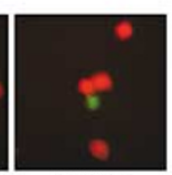

ONOO

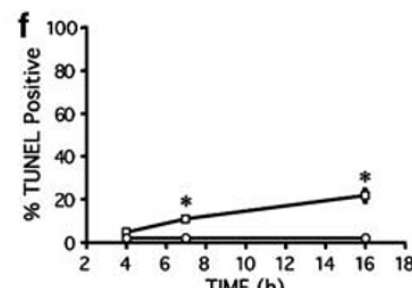

Figure 4 Peroxynitrite induced cleavage of caspases 9 and 3, cleavage of PARP and increased numbers of TUNEL-positive cells. (a) Representative Western blot indicates the appearance of the predominant cleavage product of caspase 9 , migrating at approximately $40 \mathrm{kDa}$, and that of caspase 3 , migrating at approximately $17 \mathrm{kDa}$, following treatment with $0.5 \mathrm{mM}$ peroxynitrite. Quantitative analysis of Western blot data indicates the peroxynitrite-induced increase in the ratio of cleaved to full-length caspase 9 (b) and an increase in cleaved caspase 3 (c), normalized to levels of $\beta$-tubulin. Open circles $=$ peroxynitrite. Open squares $=$ reverse order addition (REV, decomposed peroxynitrite). Results represent the mean \pm S.E.M. of three independent experiments. (d) Representative Western blot indicates cleavage of PARP $(85 \mathrm{kDa})$, which correlates temporally with the activation of caspase 3. (e) TUNEL analysis indicates the appearance of a green TUNEL-positive cell among a field of fewer total, propidium iodide-stained, attached cells $16 \mathrm{~h}$ after treatment with peroxynitrite (ONOO, right panel), in comparison to greater number of propidium iodidestained cells and the absence of TUNEL-positive cells in a matched control (REV decomposed peroxynitrite, left panel) field. Scale bar $=50 \mu \mathrm{m}$. (f) Quantitation indicates a greater number of TUNEL-positive cells at 7 and $16 \mathrm{~h}$ following treatment with peroxynitrite (open squares), as a percentage of total, propidium iodide-stained cells in comparison to REV (open circles). Results represent mean + S.E.M. of three independent experiments, and numbers of cells determined from each experiment represent an average of five fields per treatment and time point. ${ }^{*} P<0.05$ versus REV

\section{Discussion}

Studies of the morphology and DNA fragmentation of several cell types including thymocytes, HL-60 cells, cultured cortical neurons and PC12 cells first revealed a role for peroxynitrite in apoptosis. $^{5,7-9}$ When peroxynitrite is directly added to preparations of isolated mitochondria, the permeability transition pore is activated and cytochrome $c$ is released, a

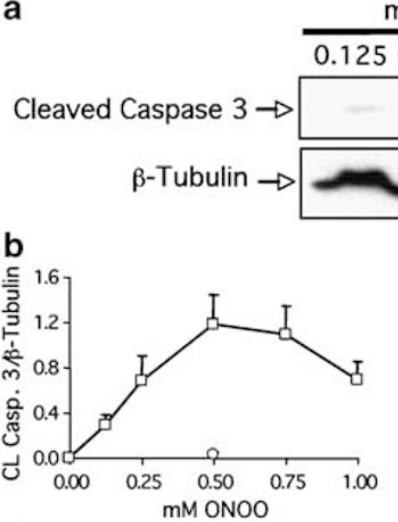

d
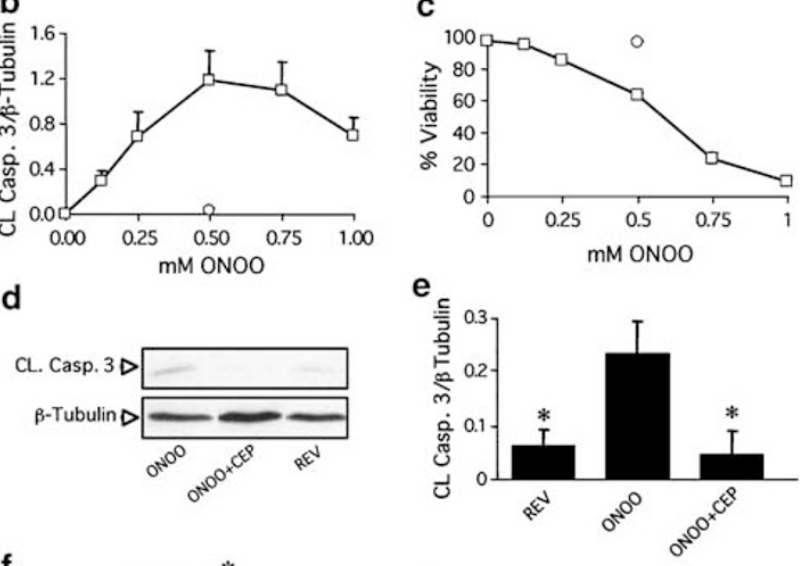

f

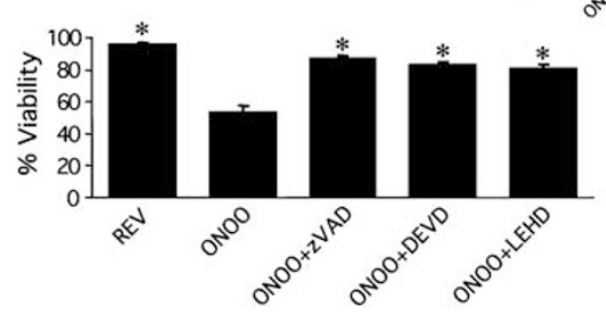

mM Peroxynitrite

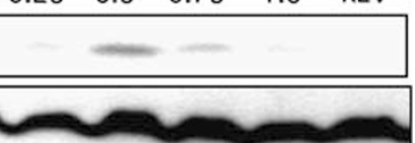

C

5 Peroxynitrite-induced cleavage of caspase 3 was dose dependent and was attenuated by inhibition of MLK. (a) Representative Western blot indicates the dose-dependent activation of caspase $3(17 \mathrm{kDa})$, measured $16 \mathrm{~h}$ following incubation with peroxynitrite. (b) Quantitative analysis of Western blot data (the ratio of cleaved caspase 3 to $\beta$-tubulin loading control) indicates that the maximal activation of caspase 3 occurs at $\geqslant 0.5 \mathrm{mM}$ peroxynitrite. (c) Peroxynitrite-induced cell death is dose dependent. Open squares $=$ peroxynitrite. Open circles $=$ reverse order addition (REV, decomposed peroxynitrite). Results represent means of three independent experiments. (d, e) Selective inhibition of MLK (CEP11004, $1.0 \mu \mathrm{M}$ ) alleviates the peroxynitrite $(0.5 \mathrm{mM})$-induced activation of caspase 3 , measured by the appearance of the $17 \mathrm{kDa}$ cleavage product and quantitatively as the ratio of cleaved caspase 3 to $\beta$-tubulin. Results represent the mean \pm S.E.M. of three independent experiments. REV = reverse order addition (decomposed peroxynitrite). (f) Inhibitors selective for caspases 3 and 9 (z-DEVD-fmk and z-LEHD-fmk, $25 \mu \mathrm{M}$ ) and the general caspase inhibitor z-VAD-fmk $(50 \mu \mathrm{M})$, all attenuated peroxynitrite $(0.5 \mathrm{mM})$-induced cell death. ${ }^{\star} P<0.05$ versus peroxynitrite. Results represent means \pm S.E.M. of duplicate measurements from at least three independent experiments

suggesting that peroxynitrite-induced apoptosis may be the result of direct oxidative damage to the mitochondria. ${ }^{17}$ However, other studies have shown that peroxynitrite-induced apoptosis could be either inhibited or enhanced by treatment with trophic factors, ${ }^{5,6}$ suggesting a regulated process. In the current study, we report that peroxynitrite activation of the intrinsic or mitochondrial apoptotic pathway in PC12 cells is preceded by phosphorylation of p38 and JNK MAPK and by translocation of phosphorylated JNK to the mitochondria. Furthermore, our study shows that the inactivation of the $\mathrm{PI}$ 3-K/Akt pathway is important in peroxynitrite-induced apoptosis. Together, these results reveal an important link between peroxynitrite-induced upstream signaling events and 

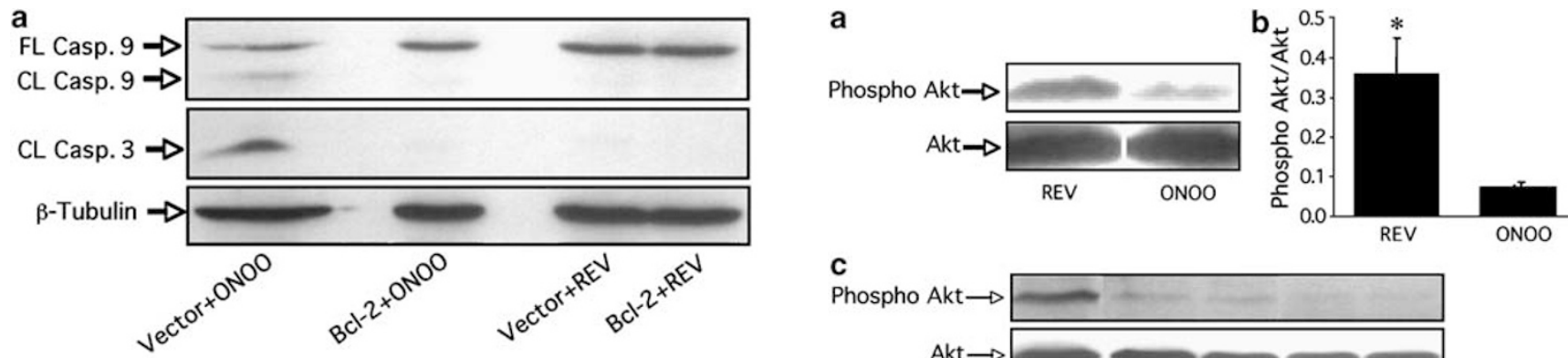

Phospho Akt $\rightarrow$

Akt $\rightarrow$

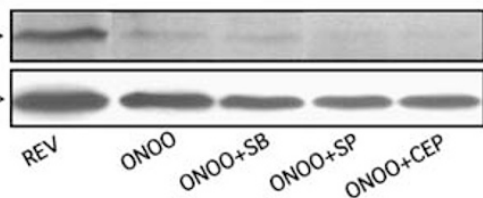

d

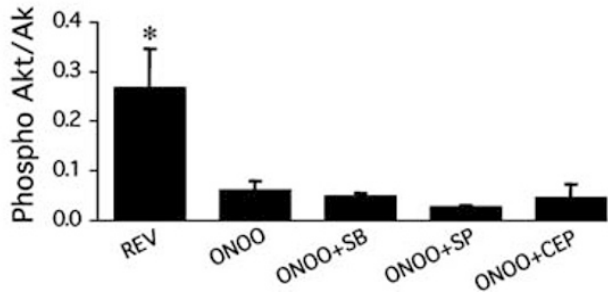

Figure 6 Overexpression of $\mathrm{Bcl}-2$ and treatment with cyclosporin A prevented peroxynitrite-induced activation of the intrinsic apoptotic pathway. (a) Representative Western blot indicates that the overexpression of Bcl-2 prevented cleavage of caspases 3 and 9 induced by $1.0 \mathrm{mM}$ peroxynitrite, in comparison to cells overexpressing vector control. REV = reverse order addition (decomposed peroxynitrite). (b) Overexpression of PC12 cells with Bcl-2 attenuated cell death induced by $1.0 \mathrm{mM}$ peroxynitrite, in comparison to cells overexpressing vector control. Reverse order addition (REV, decomposed peroxynitrite). ${ }^{*} P<0.05$ versus vector control + peroxynitrite. (c) Cyclosporin $\mathrm{A}(2.5 \mu \mathrm{M})$ attenuated peroxynitrite-induced cell death. ${ }^{*} P<0.05$ versus peroxynitrite. Results represent means \pm S.E.M. of duplicate measurements from at least three independent experiments

downstream activation of the intrinsic apoptotic pathway (Figure 9), suggesting that induction of apoptosis by peroxynitrite is not a consequence of direct effects on the mitochondria.

In our study, peroxynitrite activated p38 and JNK MAPK within minutes of treatment, as previously shown in other cell types. ${ }^{10,11,18,19}$ Peroxynitrite-induced apoptosis was already known to depend in part on p38 MAPK activation, ${ }^{18,20,21}$ but we found JNK MAPK activation to be equally important (Figures 1 and 3). Indeed, inhibition of either kinase prevented apoptosis. MLK is an upstream activator of p38 and $\mathrm{JNK}^{22}$ which regulates the intrinsic apoptotic pathway in trophic factor-deprived sympathetic neurons. ${ }^{23}$ Since the inhibition of MLK also attenuated peroxynitrite-induced apoptosis (Figures 1-3 and 5), it is presumed that peroxynitrite initiates apoptotic signaling upstream of p38 and JNK.

Results of the current study indicate that peroxynitrite not only increased the phosphorylation of total cellular JNK but also stimulated the translocation of phosphorylated p46 and p54 JNK to the mitochondrial fractions. When exposed to a variety of stress-inducing stimuli, several different cell types are known to translocate active JNK to the mitochondria. ${ }^{14,15}$ Incubation of PC12 cells with 6-hydroxydopamine was shown to lead to the selective translocation of JNK2 to mitochondria, and to the activation of the intrinsic apoptotic pathway. ${ }^{15}$ Since the antibody used in our study to detect JNK does not differentiate between JNK1 and JNK2, further studies will be
Figure 7 Peroxynitrite inactivated the Akt survival pathway, an effect not prevented by selective inhibition of MLK, p38 or JNK. (a, b) Western blot indicates the peroxynitrite $(\mathrm{ONOO}, 0.5 \mathrm{mM})$-induced dephosphorylation of Akt, measured $16 \mathrm{~h}$ following treatment. Blots for phospho-Akt were stripped and reprobed for Akt. REV = reverse order addition control (decomposed peroxynitrite). Results represent means \pm S.E.M. of three independent experiments. (c) Peroxynitrite-induced dephosphorylation of Akt was not prevented by selective inhibition of MLK (CEP-11004, $1.0 \mu \mathrm{M})$, p38 (SB203580, $1.0 \mu \mathrm{M})$ or JNK (SP600125, $0.1 \mu \mathrm{M})$. At $16 \mathrm{~h}$ following treatment, whole-cell lysates were collected for Western blot analysis of phospho-Akt and Akt, which is represented graphically in (d) as the ratio of phospho-Akt to Akt. Results represent means \pm S.E.M. of three independent experiments. ${ }^{\star} P<0.05$ in comparison to ONOO

necessary to determine whether peroxynitrite-induced apoptosis is mediated by JNK2 alone or by both kinases working in tandem.

Bax translocation plays a critical role in the mitochondriainduced release of cytochrome $c{ }^{24}$ while Bax deficiency blocks the release of cytochrome $c$ and the apoptosis induced by the transfection of JNK in mouse embryonic fibroblasts. ${ }^{25}$ In a number of different cellular models, inhibition of both JNK and p38 prevented the translocation of $\mathrm{Bax}^{25-27}$ For peroxynitrite-induced apoptosis to occur, MLK, p38 and JNK had to be simultaneously activated, inducing Bax translocation to the mitochondria. Although it is not possible to causally relate the increased phosphorylation of mitochondrial JNK and the translocation of Bax to mitochondria, it is safe to say that both events are dependent upon the activation of MLK (Figures 2 and 3).

$\mathrm{Bcl}-2$ is thought to prevent Bax from assuming its proapoptotic conformation and to inhibit the Bax-induced release of cytochrome $c .{ }^{28}$ Overexpression of $\mathrm{Bcl}-2$ has been shown previously to prevent peroxynitrite-induced apoptosis in PC12 cells and in cultured cortical neurons. ${ }^{7,29}$ Overexpression of $\mathrm{Bcl}-2$ also prevented apoptosis induced by the downregulation of SOD in PC12 cells, which promotes the endogenous production of peroxynitrite. ${ }^{30}$ Protection provided by the overexpression of $\mathrm{Bcl}-2$ further confirms that the intrinsic apoptotic pathway is activated by peroxynitrite (Figure 6). When compared to vector control, PC12 cells 


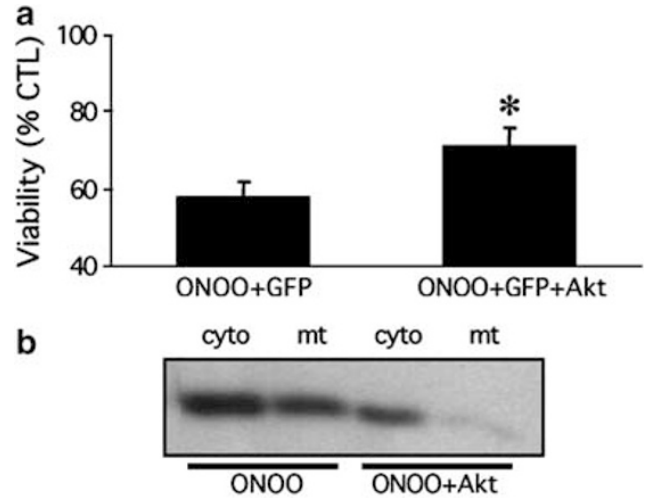

C

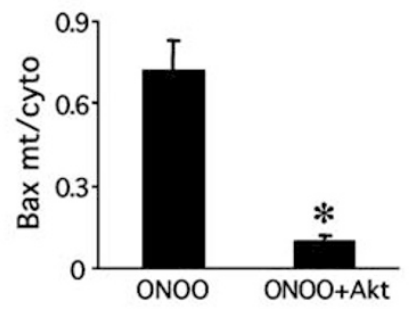

d

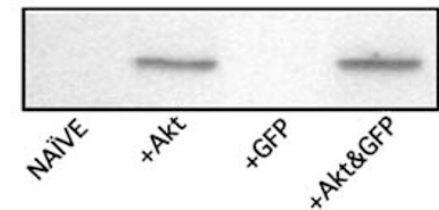

Figure 8 Overexpression of consitutively active Akt prevents peroxynitriteinduced apoptosis. (a) Transient transfection of constitutively active Akt prevents peroxynitrite-induced cell death. Percent viability was assessed $24 \mathrm{~h}$ after treatment as the ratio of GFP-positive cells in peroxynitrite (ONOO, $0.5 \mathrm{mM})$ treated cultures to that of GFP-positive cells in control (reverse order addition or decomposed peroxynitrite)-treated cells, in the presence or absence of constitutively active Akt. Data represent mean S.E.M. of five independent experiments, and numbers of GFP-positive cells determined from each experiment represent an average of five fields per treatment. ${ }^{*} P<0.05$ versus cells transfected with GFP only. (b) Representative Western blot indicates that overexpression of constitutively active Akt attenuates the translocation of Bax from cytosolic (cyto) to mitochondrial (mt) fractions collected $16 \mathrm{~h}$ following treatment with peroxynitrite $(0.5 \mathrm{mM})$, an effect that is quantitated graphically in (c). (d) Western blot for myc-tagged Akt indicates that levels of Akt were equal in cells transfected with constitutively active Akt in comparison to cotransfection of Akt and GFP. ${ }^{*} P<0.05$ versus treatment of nontransfected cells with ONOO

overexpressing Bcl-2 showed a significant reduction in cell death after incubation with $1 \mathrm{mM}$ of peroxynitrite. The varying degrees of vulnerability to peroxynitrite by naïve versus stably transformed PC12 cells may be due to inherent differences in the original clones. Nevertheless, $1 \mathrm{mM}$ concentration of peroxynitrite induced the cleavage of caspases 9 and 3 and apoptotic cell death in vector control cells, an effect that was prevented by overexpression of $\mathrm{Bcl}-2$.

Treatment with cyclosporin A also attenuated peroxynitriteinduced apoptosis in naïve PC12 cells (Figure 6), suggesting that the mitochondrial permeability transition is an important component of the intrinsic apoptotic pathway in this model. However, in addition to its induction of the intrinsic apoptotic pathway via alteration of upstream signaling events, peroxynitrite may directly alter mitochondrial function via oxidative damage, which has been reported using isolated mitochondria. ${ }^{17}$ Such direct, deleterious effects of peroxynitrite

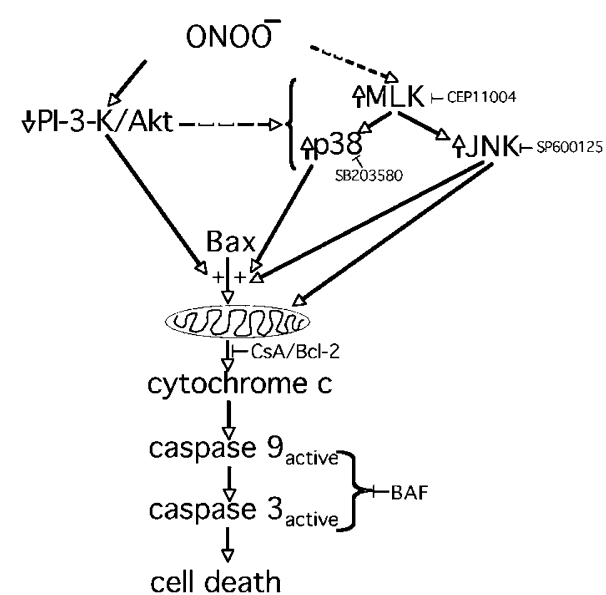

Figure 9 Model of peroxynitrite-induced apoptosis in PC12 cells. A scheme is presented summarizing the results. We suggest that activation of the MLK/p38/ JNK pathway occurs upstream of Bax translocation, cytochrome $c$ release, and caspase activation. Alterations in levels of cytosolic and mitochondrial JNK were also found which may occur dependently or independently of Bax translocation. Inactivation of the PI3-K/Akt pathway was also confirmed important for peroxynitrite-induced apoptosis. Selective inactivation of the PI3K/Akt pathway may lead to the subsequent translocation of Bax and activation of the intrinsic apoptotic pathway. Either the peroxynitrite-induced inactivation of the PI3K/Akt pathway and activation of $\mathrm{p38}$ and JNK occurs independently of each other, or the inactivation of PI3K/Akt occurs upstream of p38/JNK activation, as represented by a dashed arrow. The effects of peroxynitrite on both pathways may converge at the level of Bax translocation and cytochrome $c$ release, thus activating the intrinsic apoptotic pathway. Treatment with cyclosporin A prevented peroxynitrite-induced death, indicating that peroxynitrite may have direct effects on mitochondrial membrane permeability

on mitochondria may also be rescued by treatment with cyclosporin A. Regardless of the initiating event, our results indicate that the induction of the intrinsic apoptotic pathway by peroxynitrite is regulated by alterations in mitochondrial function (Figure 9).

Incubation of PC12 cells with peroxynitrite decreased the phosphorylation of Akt (Figure 7). The attenuation of Bax translocation and cell death by overexpression of constitutively active Akt (Figure 8) suggests a role for downregulated Akt signaling in peroxynitrite-induced induction of the intrinsic apoptotic pathway. PI3-K, the upstream activator of Akt, has been implicated previously in peroxynitrite-induced apoptosis. ${ }^{6}$ Selective inhibition of PI3-K has been shown to block the protection afforded by NGF against peroxynitrite-induced apoptosis. ${ }^{6}$ However, peroxynitrite has been shown to have no direct effect on PI3-kinase activity, ${ }^{6}$ suggesting that its effects are downstream of PI3-K and upstream of Akt. Such a supposition is further supported by the finding that the inhibition of PI3-K does not trigger apoptosis in PC12 cells. ${ }^{6}$

Activation of the PI3-K/Akt pathway has been shown to prevent apoptosis associated with the translocation of Bax and the release of cytochrome $c .{ }^{31,32}$ In contrast, downregulation of the PI3-K pathway was shown to induce both the translocation of Bax and apoptosis. ${ }^{32}$ Inactivation of Akt by peroxynitrite may result in decreased phosphorylation of its downstream target Bad. The phosphorylation of Bad is an important regulator of PI3-K/Akt-dependent survival and apoptosis. ${ }^{33}$ When not phosphorylated, Bad can displace $\mathrm{Bax}$ from Bcl-2 and $\mathrm{Bcl}-\mathrm{X}_{\mathrm{L}}$, thus allowing the formation of 
'active' homodimers of Bax, their subsequent association with mitochondria and finally the induction of apoptosis. ${ }^{24,34}$ Currently, the detection of endogenous levels of phosphorylated Bad is limited by lack of specific antibodies. ${ }^{35}$ The peroxynitrite-induced decrease in phosphorylated Akt coincided with an increase in translocation of Bax, release of cytochrome $c$ and cleavage of capsases. In the light of these studies, our current finding that peroxynitrite induces a decrease in phosphorylated Akt suggests that this event could initiate the intrinsic apoptotic pathway.

Both the MLK/p38/JNK and the PI3-K/Akt pathways have been shown to regulate peroxynitrite-induced cell death. Previous reports have shown that the inactivation of the PI3K/ Akt pathway allows for the activation of MLK and/or JNK, which leads to apoptosis. ${ }^{31,36,37}$ In the current study, inhibitors of MLK, p38 or JNK did not prevent the peroxynitrite-induced dephosphorylation of Akt but still prevented apoptosis (Figures 1 and 7). Akt dephosphorylation was not detected until $16 \mathrm{~h}$ after exposure to peroxynitrite (not shown) suggesting that inactivation of PI3-K/Akt and activation of MLK/p38/ JNK are autonomous pathways that converge, perhaps at the level of Bax translocation (Figure 9).

Results using inhibitors selective for MAPK show a clear connection between upstream activation of $\mathrm{p} 38$ and JNK, the downstream translocation of Bax and activation of caspase 3 . However, it was surprising to find a delay of several hours between peak activation of p38 and JNK and detectable cleavage of caspase 9 or 3 . The simplest explanation for this discrepancy would be that the Western blot protocol did not have the necessary sensitivity. In support of this argument and in line with previous observations, ${ }^{5}$ only a small, but significant, percentage of TUNEL-positive cells were detected $7 \mathrm{~h}$ after peroxynitrite in the current study (Figure 4), suggesting that the levels of antigen were insufficient to allow for detection of cleaved caspase via Western blot. Alternatively, this delay may have resulted from MAPK-dependent alterations in transcription or translation, which have been shown with p38 and JNK in their stress-induced synthesis of different proapoptotic molecules including Fas and Fas ligand. ${ }^{38,39}$ However, treatment with cycloheximide did not inhibit peroxynitrite-induced apoptosis (data not shown), suggesting that protein synthesis is not required for peroxynitrite-induced apoptosis.

At low concentrations, peroxynitrite predominantly induces apoptosis, while at high concentrations it predominantly triggers necrosis, as evidenced previously by morphology and by DNA laddering. ${ }^{5,7}$ Our current study confirms this interpretation by noting that peroxynitrite activates caspase 3 in a bell-shaped fashion with upstream translocation of Bax, release of cytochrome $c$ and cleavage of caspase 9 occurring at concentrations which induce maximal activation of caspase 3 .

Induction of cell death increases with increased concentrations of peroxynitrite. At concentrations that result predominantly in apoptosis, peroxynitrite may have induced some minimal necrosis when it was added to the incubation buffer. Peroxynitrite has been shown to induce minimal necrosis within a few hours of treatment at concentrations producing biochemical and morphological markers of apoptosis $24 \mathrm{~h}$ later. ${ }^{5}$ These results may explain the small but significant increase in TUNEL staining observed at $7 \mathrm{~h}$ following treatment with peroxynitrite, an increase that does not correlate temporally with caspase activation. It is well accepted that the TUNEL stain does not discriminate between apoptotic and necrotic nuclei. ${ }^{40}$

Clearly, there is evidence for the increased production of peroxynitrite in several disease states that likely contributes to their pathophysiology. The results from this study reveal that the mechanism of peroxynitrite-induced cell death is more complex than previously thought. The challenge for future studies will be to determine the existence of such regulated pathways of peroxynitrite-induced apoptosis in disease states, and if selective inhibition of these pathways will delay or prevent cell death, and ultimately the morbidity and mortality associated with such diseases.

\section{Materials and Methods}

\section{PC12 cell maintenance and treatment}

PC12 cells were maintained in RPMI 1640 medium supplemented with $10 \%$ horse serum, $5 \%$ FBS and $1 \%$ penicillin/streptomycin on collagencoated plates. For experiments, cells were plated at $30000 / \mathrm{cm}^{2}$ substrate on collagen $\left(5 \mu \mathrm{g} / \mathrm{cm}^{2}\right)$ plus poly-L-lysine $(1 \mu \mathrm{g} / \mathrm{ml})$-coated plates. At $20 \mathrm{~h}$ after plating, cells were rinsed and incubated with buffer $(50 \mathrm{mM}$ $\mathrm{Na}_{2} \mathrm{HPO}_{4}, 90 \mathrm{mM} \mathrm{NaCl}, 5 \mathrm{mM} \mathrm{KCl}, 0.8 \mathrm{mM} \mathrm{MgCl}_{2}, 1 \mathrm{mM} \mathrm{CaCl}$ ) for $1 \mathrm{~min}$, followed by a $4 \mathrm{~min}$ treatment with peroxynitrite. After treatment, peroxynitrite was aspirated and fresh culture medium was added. Selective inhibitors (CEP-11004, Cephalon, Westchester, PA, USA), SP600125 (Tocris, Ellisville, MO, USA), SB203580 and cyclosporin A (Calbiochem, La Jolla, CA, USA) were added $1 \mathrm{~h}$ prior to treatment with peroxynitrite. Previous studies have shown that SB203580 does not interfere with JNK signaling at the concentrations used in our study, ${ }^{39}$ suggesting that selective inhibition of p38 does not prevent activation of JNK.

Caspase inhibitors (z-VAD-fmk, BOC-D-fmk, z-DEVD-fmk, z-LEHDfmk, ICN) were added immediately following treatment with peroxynitrite. As controls, either decomposed peroxynitrite (reverse order addition) or no treatment was used. PC12 cells treated with staurosporine (Sigma, St Louis, MO, USA) for $6 \mathrm{~h}(1.5 \mu \mathrm{M})$ served as a positive control for biochemical measurement of apoptosis (data not shown). Dr Dale Bredesen (Buck Institute, Novato, CA, USA) kindly provided us with cells overexpressing $\mathrm{Bcl}-2$ and vector control, which were then maintained and treated similarly to naïve PC12 cells, with the modification that puromycin ( $5 \mu \mathrm{g} / \mathrm{ml}$, Sigma) was added with every media change.

\section{Transient transfection studies}

Lipofectamine 2000 diluted in Optimem media (Gibco/Invitrogen, Carlsbad, CA, USA) was added to tubes containing cDNA for constitutively active Akt $(0.8 \mu \mathrm{g} ;$ Akt-1 in Puse-Amp, Upstate Biotechnology, Charlottesville, VI, USA) and/or for green fluorescent protein (GFP; pEGFP-C1, $4 \mu \mathrm{g}$, Clontech, Palo Alto, CA, USA), according to the manufacturer's instructions, and incubated for $20 \mathrm{~min}$ at RT. Three million PC12 cells were pelleted and resuspended in serum-free RPMI, added to each of the transfection reaction vials and incubated for $5 \mathrm{~h}$ at $37^{\circ} \mathrm{C}$. After the transfection reaction, the cells were pelleted and washed, then plated either in 35-mm dishes for assessment of viability, or in 100-mm dishes for Western blot analysis. At $24 \mathrm{~h}$ after plating, PC12 cells were treated with peroxynitrite, and then 16-24 $\mathrm{h}$ later cell lysates were collected either for 
Western blot analysis, or at $24 \mathrm{~h}$ later for assessment of viability by counting numbers of GFP-positive cells in five separate fields.

\section{Assessment of cell viability}

At 16-24 $\mathrm{h}$ after treatment, cells were washed with PBS and incubated with propidium iodide ( $5 \mu \mathrm{g} / \mathrm{ml}$, Molecular Probes, Eugene, OR, USA), which stains dead or dying cells, and fluorescein diacetate $(15 \mu \mathrm{g} / \mathrm{ml}$, Molecular Probes), which is cleaved intracellularly by viable cells into the fluorescent fluorescein. In each experiment, live and dead cells were counted in five separate fields of duplicate dishes.

\section{TUNEL assay}

Up to $16 \mathrm{~h}$ following treatment with peroxynitrite, TUNEL-positive cells were counted in five separate fields using the DeadEnd ${ }^{\mathrm{TM}}$ Fluorimetric TUNEL System (Promega, Madison, WI, USA), according to the manufacturer's instructions.

\section{Western blot analysis}

Equal amounts of protein (25 $\mu \mathrm{g}$ for Bax; $50 \mu \mathrm{g}$ for p38, JNK, Akt and PARP; $75 \mu \mathrm{g}$ for Bad, cytochrome $c$, caspases), as determined using the BCA Protein Assay (Pierce, Rockford, IL, USA), were loaded and resolved using SDS-PAGE and transferred onto PVDF membranes (1.5 h, $100 \mathrm{~mA}$, constant current). Blots were blocked for $1 \mathrm{~h}$ in $5 \%$ weight/volume of milk and then incubated with primary antibody in blocking buffer (overnight, $4^{\circ} \mathrm{C}$ ). All primary antibodies used were obtained from Cell Signaling (Beverly, MA, USA) with the exception of those against cytochrome $c$ and $\beta$-III tubulin (Santa Cruz Biotechnology, Santa Cruz, CA, USA). After washing with Tris-buffered-saline containing $0.1 \%$ Tween (TBS-T), blots were incubated with secondary antibody (goat-anti-rabbit IgG, Biorad, Hecules, CA, USA) for $1 \mathrm{~h}$ at RT. Following successive washes, the signal was detected using chemiluminescence (Super Signal, Pierce). Blots analyzed for phospho-specific proteins (phospho p38, JNK and Akt) were stripped (Restore Western Blot Stripping Buffer, Pierce) and subsequently probed for total p38, JNK or Akt. Western blot data were quantified using Quantity One Software (Biorad).

\section{Analysis of cytosolic versus nuclear fractions}

Cells were detached from the substrate and collected by centrifugation $\left(600 \times g, 5 \mathrm{~min}, 4^{\circ} \mathrm{C}\right)$. The pellets were washed with $1 \mathrm{ml}$ of ice-cold PBS and collected again via centrifugation $\left(600 \times g, 5 \mathrm{~min}, 4^{\circ} \mathrm{C}\right)$ and resuspended in lysis buffer containing $25 \mathrm{mM}$ HEPES, $5 \mathrm{mM} \mathrm{MgCl}$, $2 \mathrm{mM}$ EDTA, $2 \mathrm{mM}$ DTT, $1 \mathrm{mM}$ PMSF, $1 \mathrm{mM}$ sodium orthovanadate, and $1 \%$ protease inhibitor cocktail (Sigma). For protein collected as cytosolic (caspases, p38, JNK) versus nuclear (PARP) fractions, lysates of $4.5 \times 10^{6}$ cells were sonicated and then centrifuged (10000 r.p.m., $10 \mathrm{~min}, 4^{\circ} \mathrm{C}$ ). The supernatant was transferred (cytosolic fraction) and then the pellet (nuclear fraction) was resuspended in lysis buffer containing $1 \%$ Triton X-100.

\section{Analysis of whole-cell lysates}

Whole-cell lysates of $3 \times 10^{6}$ cells were collected for analysis of Akt, Bax and Bad. The lysis buffer for whole-cell lysates contained $1 \%$ SDS and $1 \%$ Triton X-100. After sonication, lysates were centrifuged as above, and the supernatant was collected.
Analysis of mitochondrial versus cytosolic fractions via subcellular fractionation

For mitochondrial versus cytosolic determination of Bax and cytochrome $c$, $250 \mathrm{mM}$ of sucrose was added to the lysis buffer. Lysates of $6 \times 10^{6}$ cells were transferred to a cell cavitation bomb (Parr Instrument Co.); 400 psi of nitrogen gas was applied to the chamber for $4 \mathrm{~min}$ to break open the cell, leaving the mitochondria intact. After a subsequent spin (10000 r.p.m., $10 \mathrm{~min}, 4^{\circ} \mathrm{C}$ ), the supernatant (cytosolic fraction) was cleared of microsomes (15000 r.p.m., $30 \mathrm{~min}, 4^{\circ} \mathrm{C}$ ), and the pellet (mitochondrial fraction) was resuspended in lysis buffer containing $1 \%$ Triton X-100. Subsets of cells were alternatively collected for intracellular localization of JNK and phospho-JNK. In brief, $5 \times 10^{7}$ cells were collected by centrifugation $\left(600 \times g, 5 \mathrm{~min}, 4^{\circ} \mathrm{C}\right)$; the pellets were washed with $10 \mathrm{ml}$ of ice-cold PBS and collected again via centrifugation $(600 \times g, 5 \mathrm{~min}$, $4^{\circ} \mathrm{C}$ ). Pellets were then resuspended in $1 \mathrm{ml}$ of Cytosol Extraction Buffer (BioVision, Mountain View, CA, USA) for $10 \mathrm{~min}$ before lysates were prepared using a glass tissue grinder. The lysates were centrifuged at $700 \times g$ for 10 min at $4^{\circ} \mathrm{C}$ and the supernatants were used for total protein. To separate mitochondrial and cytosolic fractions, the supernatants were centrifuged at $10000 \times g$ for $35 \mathrm{~min}$ at $4^{\circ} \mathrm{C}$, the supernatants were saved as the cytosolic fraction. The resultant pellets (mitochondrial fraction) were resuspended in Mitochondrial Extraction Buffer (BioVision).

\section{Statistics}

Effects of peroxynitrite versus control were analyzed for significance using the Student's unpaired $t$ test. Group-wise comparisons were analyzed for significance via one factor analysis of variance (ANOVA) with post hoc comparisons conducted via either Dunnet's Multiple Comparison test (when compared only to peroxynitrite alone) or via Bonferonni's post hoc test (when making multiple comparisons between groups). In all cases, a $P$-value of less than or equal to 0.05 was considered significant.

\section{Acknowledgements}

We thank Dr Kevin A Roth (University of Alabama at Birmingham) and Dr Joseph S Beckman (Oregon State University) for their critical comments on the experimental results and the manuscript, and Patricia Matthews, Dr Kimberly McGhee and Wayne Kleinman for their help in the preparation and for editing this manuscript. We thank the reviewers for their insightful comments and critiques, which greatly helped to improve our manuscript and the quality of the results. We also thank Steve Trusko from Cephalon for generously providing us with the CEP-11004. This work was supported by grants from the NIH/NINDS NS42834 and NS36761 (AGE).

\section{References}

1. Beckman JS and Koppenol WH (1996) Nitric oxide, superoxide, and peroxynitrite: the good, the bad, and ugly. Am. J. Physiol. 271: C1424-C1437

2. Radi R, Beckman JS, Bush KM and Freeman BA (1991) Peroxynitrite-induced membrane lipid peroxidation: the cytotoxic potential of superoxide and nitric oxide. Arch. Biochem. Biophys. 288: 481-487

3. Ischiropoulos H (1998) Biological tyrosine nitration: a pathophysiological function of nitric oxide and reactive oxygen species. Arch. Biochem. Biophys. 356: $1-11$

4. Schopfer FJ, Baker PR and Freeman BA (2003) NO-dependent protein nitration: a cell signaling event or an oxidative inflammatory response? Trends Biochem. Sci. 28: 646-654 
5. Estevez AG, Radi R, Barbeito L, Shin JT, Thompson JA and Beckman JS (1995) Peroxynitrite-induced cytotoxicity in PC12 cells: evidence for an apoptotic mechanism differentially modulated by neurotrophic factors. J. Neurochem. 65: 1543-1550

6. Spear N, Estevez AG, Barbeito L, Beckman JS and Johnson GV (1997) Nerve growth factor protects $\mathrm{PC} 12$ cells against peroxynitrite-induced apoptosis via a mechanism dependent on phosphatidylinositol 3-kinase. J. Neurochem. 69: 53-59

7. Bonfoco E, Krainc D, Ankarcrona M, Nicotera P and Lipton SA (1995) Apoptosis and necrosis: two distinct events induced, respectively, by mild and intense insults with $\mathrm{N}$-methyl-D-aspartate or nitric oxide/superoxide in cortical cell cultures. Proc Natl Acad Sci USA 92: 7162-7166

8. Lin KT, Xue JY, Nomen M, Spur B and Wong PY (1995) Peroxynitrite-induced apoptosis in HL-60 cells. J. Biol. Chem. 270: 16487-16490

9. Salgo MG, Squadrito GL and Pryor WA (1995) Peroxynitrite causes apoptosis in rat thymocytes. Biochem. Biophys. Res. Commun. 215: 1111-1118

10. Jope RS, Zhang $L$ and Song $L(2000)$ Peroxynitrite modulates the activation of p38 and extracellular regulated kinases in PC12 cells. Arch. Biochem. Biophys. 376: $365-370$

11. Go YM, Patel RP, Maland MC, Park H, Beckman JS, Darley-Usmar VM and Jo $\mathrm{H}$ (1999) Evidence for peroxynitrite as a signaling molecule in flow-dependent activation of c-Jun NH(2)-terminal kinase. Am. J. Physiol. 277: H1647-H1653

12. Yao R and Cooper GM (1995) Requirement for phosphatidylinositol-3 kinase in the prevention of apoptosis by nerve growth factor. Science 267: 2003-2006

13. Xia Z, Dickens M, Raingeaud J, Davis RJ and Greenberg ME (1995) Opposing effects of ERK and JNK-p38 MAP kinases on apoptosis. Science 270: 13261331

14. Kharbanda S, Saxena S, Yoshida K, Pandey P, Kaneki M, Wang Q, Cheng K, Chen YN, Campbell A, Sudha T, Yuan ZM, Narula J, Weichselbaum R, Nalin C and Kufe D (2000) Translocation of SAPK/JNK to mitochondria and interaction with $\mathrm{Bcl}-\mathrm{x}(\mathrm{L})$ in response to DNA damage. J. Biol. Chem. 275: 322-327

15. Eminel S, Klettner A, Roemer L, Herdegen T and Waetzig V (2004) JNK2 translocates to the mitochondria and mediates cytochrome $c$ release in $\mathrm{PC} 12$ cells in response to 6-hydroxydopamine. J. Biol. Chem. 279: 55385-55392

16. Bal-Price $A$ and Brown GC (2000) Nitric-oxide-induced necrosis and apoptosis in PC12 cells mediated by mitochondria. J. Neurochem. 75: 1455-1464

17. Brookes PS and Darley-Usmar VM (2004) Role of calcium and superoxide dismutase in sensitizing mitochondria to peroxynitrite-induced permeability transition. Am. J. Physiol. Heart Circ. Physiol. 286: H39-H46

18. Nabeyrat E, Jones GE, Fenwick PS, Barnes PJ and Donnelly LE (2003) Mitogen-activated protein kinases mediate peroxynitrite-induced cell death in human bronchial epithelial cells. Am. J. Physiol. Lung Cell Mol. Physiol. 284: L1112-L1120

19. Zhang $\mathrm{Y}$, Wang H, Li J, Jimenez DA, Levitan ES, Aizenman E and Rosenberg PA (2004) Peroxynitrite-induced neuronal apoptosis is mediated by intracellular zinc release and 12-lipoxygenase activation. J. Neurosci. 24: 10616-10627

20. Oh-hashi K, Maruyama W, Yi H, Takahashi T, Naoi M and Isobe K (1999) Mitogen-activated protein kinase pathway mediates peroxynitrite-induced apoptosis in human dopaminergic neuroblastoma SH-SY5Y cells. Biochem. Biophys. Res. Commun. 263: 504-509

21. Sarker KP, Nakata M, Kitajima I, Nakajima T and Maruyama I (2000) Inhibition of caspase-3 activation by SB 203580, p38 mitogen-activated protein kinase inhibitor in nitric oxide-induced apoptosis of PC-12 cells. J. Mol. Neurosci. 15: 243-250

22. Tibbles LA, Ing YL, Kiefer F, Chan J, Iscove N, Woodgett JR and Lassam NJ (1996) MLK-3 activates the SAPK/JNK and p38/RK pathways via SEK1 and MKK3/6. EMBO J. 15: 7026-7035
23. Harris CA, Deshmukh M, Tsui-Pierchala B and Maroney AC and Johnson Jr EM (2002) Inhibition of the c-Jun $N$-terminal kinase signaling pathway by the mixed lineage kinase inhibitor CEP-1347 (KT7515) preserves metabolism and growth of trophic factor-deprived neurons. J. Neurosci. 22: 103-113

24. Gross A, Jockel J, Wei MC and Korsmeyer SJ (1998) Enforced dimerization of BAX results in its translocation, mitochondrial dysfunction and apoptosis. EMBO J. 17: 3878-3885

25. Lei K, Nimnual A, Zong WX, Kennedy NJ, Flavell RA, Thompson CB, Bar-Sagi $D$ and Davis RJ (2002) The Bax subfamily of Bcl2-related proteins is essential for apoptotic signal transduction by c-Jun NH(2)-terminal kinase. Mol. Cell. Biol. 22: 4929-4942

26. Ghatan S, Larner S, Kinoshita Y, Hetman M, Patel L, Xia Z, Youle RJ and Morrison RS (2000) p38 MAP kinase mediates bax translocation in nitric oxideinduced apoptosis in neurons. J. Cell Biol. 150: 335-347

27. Shou Y, Li L, Prabhakaran K, Borowitz JL and Isom GE (2003) p38 Mitogenactivated protein kinase regulates Bax translocation in cyanide-induced apoptosis. Toxicol. Sci. 75: 99-107

28. Cheng EH, Wei MC, Weiler S, Flavell RA, Mak TW, Lindsten T and Korsmeyer SJ (2001) BCL-2, BCL-X(L) sequester BH3 domain-only molecules preventing BAX- and BAK-mediated mitochondrial apoptosis. Mol. Cell 8: 705-711

29. Deng G, Su JH, Ivins KJ, Van Houten B and Cotman CW (1999) Bcl-2 facilitates recovery from DNA damage after oxidative stress. Exp. Neurol. 159: 309-318

30. Troy CM, Derossi D, Prochiantz A, Greene LA and Shelanski ML (1996) Downregulation of $\mathrm{Cu} / \mathrm{Zn}$ superoxide dismutase leads to cell death via the nitric oxide-peroxynitrite pathway. J. Neurosci. 16: 253-261

31. Molton SA, Todd DE and Cook SJ (2003) Selective activation of the c-Jun Nterminal kinase (JNK) pathway fails to elicit Bax activation or apoptosis unless the phosphoinositide $3^{\prime}$-kinase (PI3K) pathway is inhibited. Oncogene 22 : 4690-4701

32. Tsuruta F, Masuyama $\mathrm{N}$ and Gotoh $\mathrm{Y}$ (2002) The phosphatidylinositol 3-kinase (PI3K)-Akt pathway suppresses Bax translocation to mitochondria. J. Biol. Chem. 277: 14040-14047

33. Datta SR, Dudek H, Tao X, Masters S, Fu H, Gotoh $Y$ and Greenberg ME (1997) Akt phosphorylation of BAD couples survival signals to the cell-intrinsic death machinery. Cell 91: 231-241

34. Yang E, Zha J, Jockel J, Boise LH, Thompson CB and Korsmeyer SJ (1995) $\mathrm{Bad}$, a heterodimeric partner for $\mathrm{Bcl}-\mathrm{XL}$ and $\mathrm{Bcl}-2$, displaces Bax and promotes cell death. Cell 80: 285-291

35. Putcha GV, Harris CA, Moulder KL, Easton RM, Thompson CB and Johnson Jr EM (2002) Intrinsic and extrinsic pathway signaling during neuronal apoptosis: lessons from the analysis of mutant mice. J. Cell Biol. 157: 441-453

36. Barthwal MK, Sathyanarayana P, Kundu CN, Rana B, Pradeep A, Sharma C, Woodgett JR and Rana A (2003) Negative regulation of mixed lineage kinase 3 by protein kinase B/AKT leads to cell survival. J. Biol. Chem. 278: 3897-3902

37. Okubo Y, Blakesley VA, Stannard B, Gutkind S and Le Roith D (1998) Insulinlike growth factor-I inhibits the stress-activated protein kinase/c-Jun $N$-terminal kinase. J. Biol. Chem. 273: 25961-25966

38. Raoul C, Henderson CE and Pettmann B (1999) Programmed cell death of embryonic motoneurons triggered through the Fas death receptor. J. Cell Biol. 147: 1049-1062

39. Le-Niculescu H, Bonfoco E, Kasuya YI, Claret FX, Green DR and Karin M (1999) Withdrawal of survival factors results in activation of the JNK pathway in neuronal cells leading to Fas ligand induction and cell death. Mol. Cell. Biol. 19: $751-763$

40. Grasl-Kraupp B, Ruttkay-Nedecky B, Koudelka H, Bukowska K, Bursch W and Schulte-Hermann R (1995) In situ detection of fragmented DNA (TUNEL assay) fails to discriminate among apoptosis, necrosis, and autolytic cell death: a cautionary note. Hepatology 21: 1465-1468 